16 - ORIGINAL ARTICLE WOUND HEALING

\title{
Morphologic evaluation of the use of a latex prosthesis in videolaparoscopic inguinoplasty. An experimental study in $\operatorname{dogs}{ }^{1}$
}

\author{
Avaliação morfológica da utilização de prótese de latex na inguinoplastia videolaparoscópica. \\ Estudo experimental em cães
}

\author{
Luiz Henrique de Sousa ${ }^{I}$, Reginaldo Ceneviva ${ }^{I I}$, Joaquim Coutinho Netto ${ }^{\mathrm{III}}$, Fátima MruéIV, Luiz Henrique de Sousa Filhov \\ Orlando de Castro e Silva ${ }^{\text {VI }}$ \\ IFellow, Clinical Surgery Course, Department of Surgery and Anatomy, FMRP-USP, Ribeirao Preto-SP, Brazil. Responsible for the intellectual \\ and scientific content of the study, acquisition and interpretation of data \\ ${ }^{\mathrm{II}}$ Chairman, Full Professor and Volunteer Faculty, Division of Digestive Surgery, Department of Surgery and Anatomy, FMRP-USP, Ribeirao \\ Preto-SP, Brazil. Supervised all phases of the study, critical revision. \\ IIIFull Professor, Department of Biochemistry, FMRP-USP, Ribeirao Preto-SP, Brazil. Helped with technical procedures, collection and processing \\ of study informations.

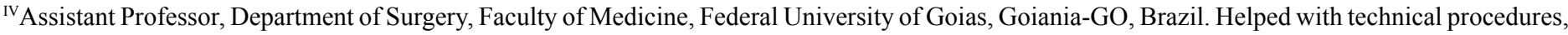 \\ collection and processing of study information. \\ ${ }^{\mathrm{v}} \mathrm{MD}$, Digestive Surgery and Obesity Clinic of Goiania, Goias, Brazil. Involved with technical procedures. \\ ${ }^{\mathrm{VI}}$ Full Professor, Head Division of Gastroenterology, Department of Surgery and Anatomy, Coordinator Liver Transplant Program, FMRP-USP, \\ Ribeirao Preto-SP, Brazil. Critical revision.
}

\begin{abstract}
PURPOSE: To evaluate the morphological aspects of the behavior of 4 types of latex biomembranes implanted in preperitoneal videolaparoscopic inguinoplasty.

METHODS: Sixteen inguinoplasties were performed in 12 dogs: group 1 received an impermeable latex biomembrane in the right inguinal region and a prolene prosthesis, as control, in the contralateral inguinal region; groups 2, 3 and 4 received latex biomembranes respectively containing impermeable polyamide, $1-\mathrm{mm}$ thick porous polyamide and $0.5-\mathrm{mm}$ thick porous polyamide. Macro- and microscopic evaluations of the inguinal region and of the removed implants were made on the $7^{\text {th }}, 14^{\text {th }}, 21^{\text {st }}$ and $28^{\text {th }}$ days in group 1 and on the $28^{\text {th }}$ postoperative day in the other groups.

RESULTS: We observed absence of hematoma, seroma and infection; presence of tortuosities; induction of vascular neoformation, inflammatory reaction and collagen deposition, and full encystment of the latex biomembranes, except that with fine porous polyamide, which was partially incorporated, with the formation of microcysts. No latex biomembrane induced fibrosis as observed in the prolene control group.
\end{abstract}

CONCLUSIONS: The biomembranes maintain induction of the healing process without fibrosis, are fully encysted and, except for the one with fine porous polyamide, are not incorporated into adjacent tissues. The latex biomembrane, with or without polyamide, is not recommended as a separate material for preperitoneal inguinoplasty.

Key words: Hernia. Latex. Surgical Procedure. Surgical Laparoscopy. Dogs.

\section{RESUMO}

OBJETIVO: Avaliar aspectos morfológicos do comportamento de 4 tipos de biomembranas de latex, colocadas pré-peritonealmente em cães, por inguinoplastia videolaparoscópica.

MÉTODOS: Dezesseis inguinoplastias em 12 cães: grupo 1, com biomembrana de latex impermeável inguinal direita em quatro cães e prótese de prolene, como controle, contra-lateral; grupos 2, 3 e 4, com biomembrana de latex respectivamente de poliamida impermeável, poliamida porosa com $1 \mathrm{~mm}$ de espessura e poliamida porosa com $0,5 \mathrm{~mm}$ de espessura. Avaliou-se a região inguinal e as peças retiradas macro e microscopicamente, no grupo 1 no $7^{\circ}, 14^{\circ}, 21^{\circ}$ e $28^{\circ}$ dias e nos demais grupos no $28^{\circ}$ dia pós-operatório.

RESULTADOS: ausência de hematoma, seroma e infecção; presença de tortuosidade; indução de neoformação vascular, reação inflamatória, deposição de colágeno e encistamento total das biomembranas de latex, exceto com poliamida porosa fina que se incorporou apenas parcialmente, com formação de microcistos. Nenhuma biomembrana de latex induziu fibrose como no grupo controle prolene. CONCLUSÕES: As biomembranas mantêm indução do processo de cicatrização sem fibrose, sofrem encistamento e, exceto com poliamida porosa fina, não se incorporam aos tecidos vizinhos. A biomembrana de latex, com e sem poliamida, isoladamente não é recomendada para inguinoplastia pré-peritoneal.

Descritores: Hérnia. Latex. Procedimento Cirúrgico. Cirurgia Laparoscópica. Cães. 


\section{Introduction}

Etiopathogenically, inguinal hernias are related to areas of the inguinal region weakened by elastase deficiency. However, the increase in intra-abdominal pressure in patients with pulmonary emphysema, prostate hypertrophy and asthma, as well as malformation of the transverse abdominal muscle and collagen deficiency, favor the appearance of hernias.

Surgical treatment is performed in order to create local mechanical barriers that will strengthen the region. In 1884, Edoardo Bassini developed his operation, followed by other surgeons who used tissues of the inguinal region itself for reinforcement, such as transverse fascia, pectineal ligament, aponeurosis of the external oblique muscle, conjoint tendon, and internal inguinal ring $^{1-3}$.

In an attempt to improve the results, especially regarding recurrence, prostheses started to be applied in order to obtain a resistant tissue able to create a mechanical obstacle to the abdominal viscera. Different types of prostheses, absorbable or not, synthetic, biosynthetic and biological were tested on the abdominal wall and in the inguinal region ${ }^{4-7}$. The absorbable synthetic prostheses most frequently used consist of polygalactin and polyglycolic acid. The non-absorbable ones are made of polytetrafluoroethylene (PTFE, Gore-tex and Teflon), polypropylene (Marlex, Trelex and Prolene), polyethylene, nylon, polyester, dacron, and mersilene.

The biological products experimentally used on the abdominal wall and in the inguinal region were skin grafts, fascia lata, pedicled transplants of the sheath of the abdominal rectus muscle, seromuscular transplants of the small intestine, dura mater and bovine pericardium, all inducing reasonable rates of complications ${ }^{6}$.

Impermeable prostheses induce the formation of cysts that may become infected by contamination during handling, but this does not mean that they are rejected. Stoppa ${ }^{8}$ used a porous dacron and mersilene prosthesis in the preperitoneal space of the inguinal region through an infraumbilical laparotomy approach, without fixing it to adjacent tissues, and defined this method as "a rubber patch between the inner tube and the tire". The development of connective tissue through the mesh or pores occurred rapidly, preventing the migration or extrusion of the prosthesis. The author then concluded that the evaluation of aspects such as the integration or incorporation of prostheses into adjacent tissues, inflammatory response, formation of adhesions and induction of complications is an attempt to look for better results in the treatment of hernia defects by comparing different types of prostheses.

Lichtenstein et al. ${ }^{8}$ introduced the principle of the "tension-free" technique by reinforcing the floor of the inguinal region with the use of a prosthesis in all cases, with low complication rates. The numerous advantages of the videolaparoscopic approach over open surgery in various abdominal procedures have been extensively discussed and demonstrated in the 1990 decade. These advantages have contributed to the propagation of the method in various abdominal procedures, including inguinal hernioplasty.

The preperitoneal approach to the inguinal region described by Nyhus ${ }^{4}$, the "tire patch" principle of Stoppa et al. ${ }^{9}$ and the principle of the "tension-free" technique of Lichtenstein et $a l .{ }^{8}$, together with the advantages of videolaparoscopic surgery, have guided the development of videolaparoscopic techniques for access to this region.

The technique most frequently used today is the transabdominal preperitoneal (TAPP) one ${ }^{10,11}$ and its main complications are seromas, hematomas and bladder intrusion ${ }^{12}$.

A biosynthetic prosthesis made of latex extracted from Hevea brasilienses, to which the synthetic protein polylysine was added, was described in 1996. Mrué ${ }^{13}$ used in the esophagus of dogs and observed angiogenesis and formation of esophageal mucosa and of muscle fibers. After the report of Mrué, several authors studied the latex prosthesis with polylysine in other situations, demonstrating results such as the induction of angiogenic activity, the formation of a provisional matrix and cell adhesion, complete granuulation of a peritoneostomy in dogs, healing of leg ulcers, closure of the perforations of the tympanic membrane inducing granulation, induction of myointimal proliferation, endothelialization and deposition of a connective support fibrin matrix in a femoral artery, excellent biocompatibility in experimental pericardium replacement, possibility of use as a vascular implant and as a support for transplants of isolated encapsulated cells, and facilitation of the process of tissue neoformation but not of the formation of fistulae when in contact with abdominal viscera ${ }^{14-15}$.

New investigations with the use of this biomembrane placed in the inguinal region by videolaparoscopy are justified by the following findings: the polypropylene prosthesis is used almost all over the world but there is no ideal prosthesis for use in the inguinal region ${ }^{16}$, the videolaparoscopic approach has advantages over open surgery ${ }^{10,17}$, the latex biomembrane has shown good results regarding vessel neoformation, inflammatory reaction, collagen deposition and consequent healing and all studies performed with a latex biomembrane have used it as a substitute of a biological tissue, and no studies have assessed its morphological aspects and its behavior when placed between biological tissue, but without replacing them ${ }^{13,15}$. Our objective was to assess the morphological aspects of the behavior of impermeable latex biomembranes, latex biomembranes with impermeable polyamide and latex biomembranes with porous polyamide in dogs submitted to videolaparoscopic inguinoplasty with placement of a prosthesis in the preperitoneal space.

\section{Methods}

Adult male mongrel dogs with no inguinal hernia were used. All animals were treated according to the Ethics Code for Animal Experimentation of the World Health Organization ${ }^{18}$.

Sixteen inguinoplasties were performed by the preperitoneal transabdominal technique in 12 dogs divided into the following four groups:

GROUP $1(\mathrm{n}=8)$ : the impermeable latex biomembrane was placed in the preperitoneal space of the right inguinal region and the prolene prosthesis, as control, was placed in the left inguinal region of dogs nos. 1, 2, 3 and 4. Microscopically, the prolene prosthesis consists of a mesh that renders it porous and permeable. The original latex biomembrane was developed and manufactured in the laboratory of the Department of Biochemistry, Faculty of Medicine of Ribeirão Preto, University of São Paulo using latex extracted from the rubber tree Hevea brasiliensis ${ }^{13}$. Microscopically, the surface is irregular and has no pores (Figure 1). 


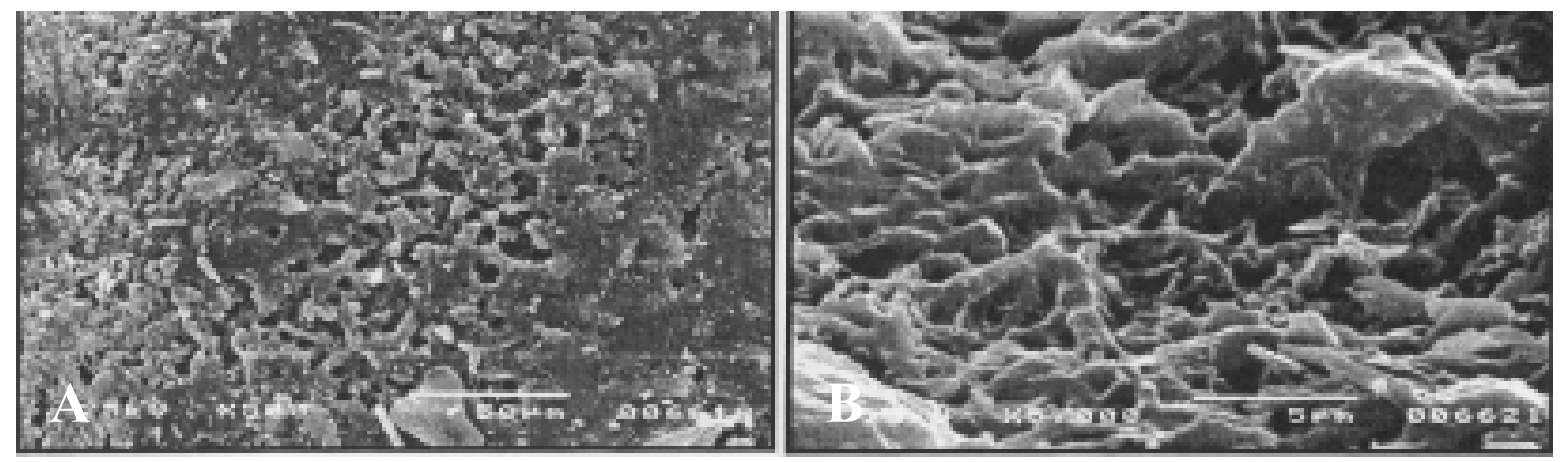

FIGURE 1- Electron photomicrographs of the latex prosthesis with impermeable polyamide. A - Irregular outer surface (500x). B - Detail of the irregular aspect with elevations and depressions (1.500x). Reproduced from Mrué et al. ${ }^{13}$, with permission

The remaining groups were formed based on the results obtained with the previous group, with an attempt to improve them by modifying the structure of the latex biomembrane. Polyamide was added to the latex membrane in order to serve as a "skeleton", providing more rigidity. Microscopically, its surface is irregular and has no pores. It is impermeable and the latex completely envelopes the two "nylon stocking" surfaces as well as its filaments.

GROUP $2(n=4)$ : the latex membrane with the impermeable polyamide "skeleton" was placed in the preperitoneal space of the left inguinal region of dogs numbers 5, 6, 7 and 8 .

Still in order to improve the results of the previous groups regarding stretched accommodation and incorporation of the biomembrane, pores were created in the latex biomembrane with impermeable polyamide.
GROUP $3(n=2)$ : the latex biomembrane with thick (1$\mathrm{mm}$ thickness) porous polyamide was placed in the preperitoneal space of the left inguinal region of dogs numbers 9 and 10.

GROUP $4(\mathrm{n}=2)$ : the latex membrane with fine $(0.5$ $\mathrm{mm}$ thick) porous polyamide was in the preperitoneal space of the left inguinal region of dogs numbers 11 and 12 .

Microscopically, the latex biomembrane with porous polyamide has a polyamide skeleton whose filaments are enveloped by latex, forming pores and thus permitting permeability. Thickness is the only difference between the $1 \mathrm{~mm}$ and $0.5 \mathrm{~mm}$ membranes (Figure 2).

The prolene prosthesis and all biomembranes applied to the dogs measured $4 \times 4 \mathrm{~cm}$ (Figure 3).
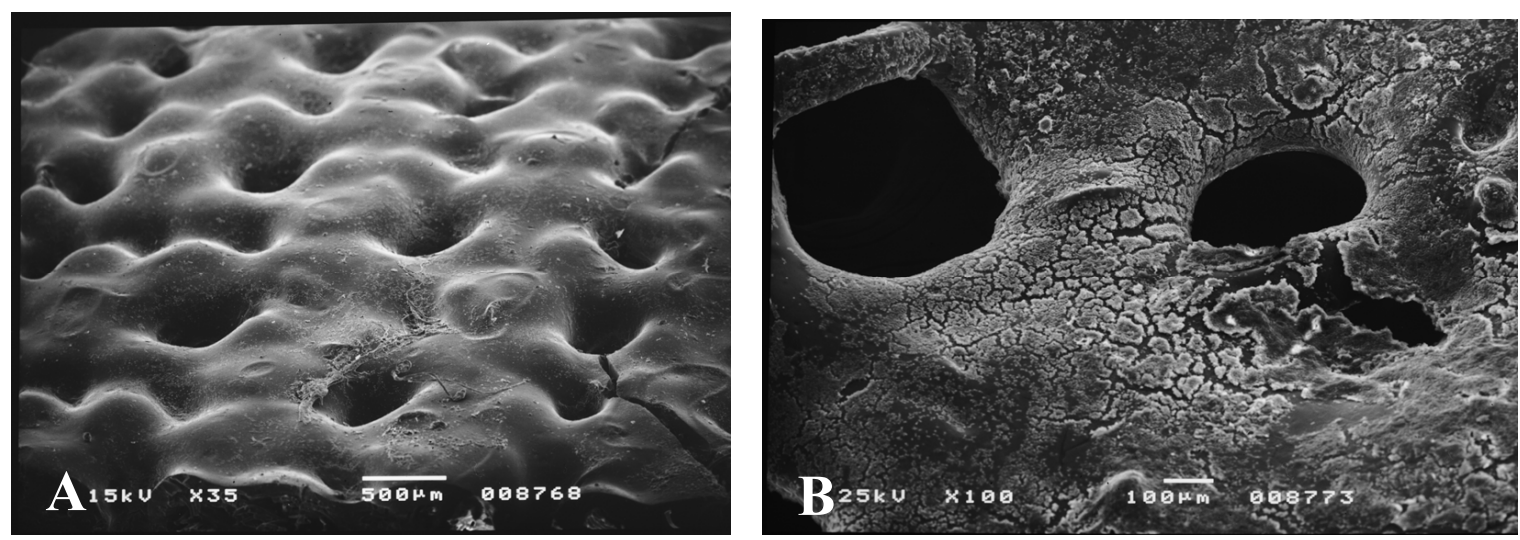

FIGURE 2 - Electron photomicrographs of the latex prosthesis with porous polyamide.: A - Inclined panoramic view of the surface of the 1-mm thick biomembrane (35x). B - Inclined panoramic view of the surface of the $0.5-\mathrm{mm}$ thick biomembrane (100x). Reproduced from Mrué et al. ${ }^{13}$, with permission 

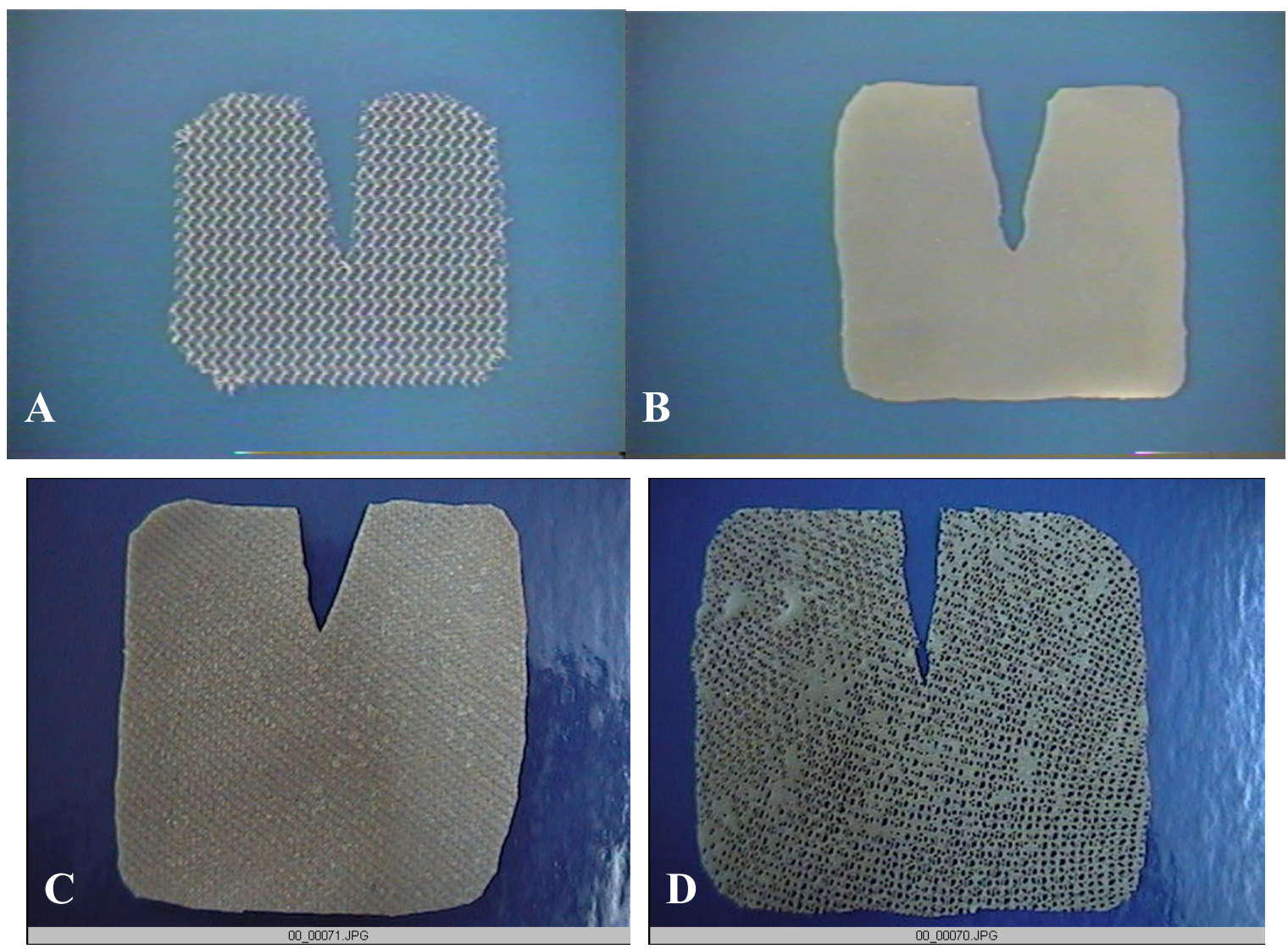

FIGURE 3 - Macroscopic aspect of the prostheses. A - Prolene; B - Impermeable latex biomembrane; C - Latex biomembrane with impermeable polyamide; D - Latex biomembrane with polyamide containing 0.5 -mm pores

The behavior of the latex biomembranes and of the prolene prosthesis was assessed by: 1 - study of the external macroscopic aspect of the inguinal region; 2 - macroscopic study of the removed specimens to determine accommodation, encystment and incorporation; and 3 - microscopic aspect of the tissues of the inguinal region to determine the healing process and the incorporation of the net into the adjacent tissues.

After anesthesia, the inguinal regions were examined for complications such as seromas, hematomas and infection. Next, the dogs were euthanized with an intravenous overdose of thiopental sodium and a median infraumbilical laparotomy was performed in each animal. The inguinal regions were observed, the specimens including all the layers of the abdominal wall except the skin were removed and the following aspects were examined: peritoneal integrity, epiploon adherences, visceral adherences, and prosthesis accommodation, encystment and incorporation.

In group 1 the right and left inguinal regions were evaluated in the following chronological order in relation to the postoperative day: dog number 1,7 th day; dog number 2,14 th day; dog number 3, 21st day; dog number 4, 28th day. In the remaining groups, the evaluations were performed on the 28th postoperative day.

After macroscopic analysis, fragments of the specimens were examined by light microscopy to evaluate the following aspects: vascular neoformation, inflammatory reaction, collagen deposit, fibrosis, and prosthesis encystment and incorporation.

\section{Results}

GROUP 1: There was no macroscopic evidence of complications such as seromas, hematomas or infection at any time point evaluated.

With the impermeable latex biomembrane, the peritoneum remained intact, with aherence of the epiploonom in all cases. There was no visceral adherence. The prosthesis became tortuous and total encystment occurred in all dogs at all four time points evaluated (Figure 4). 

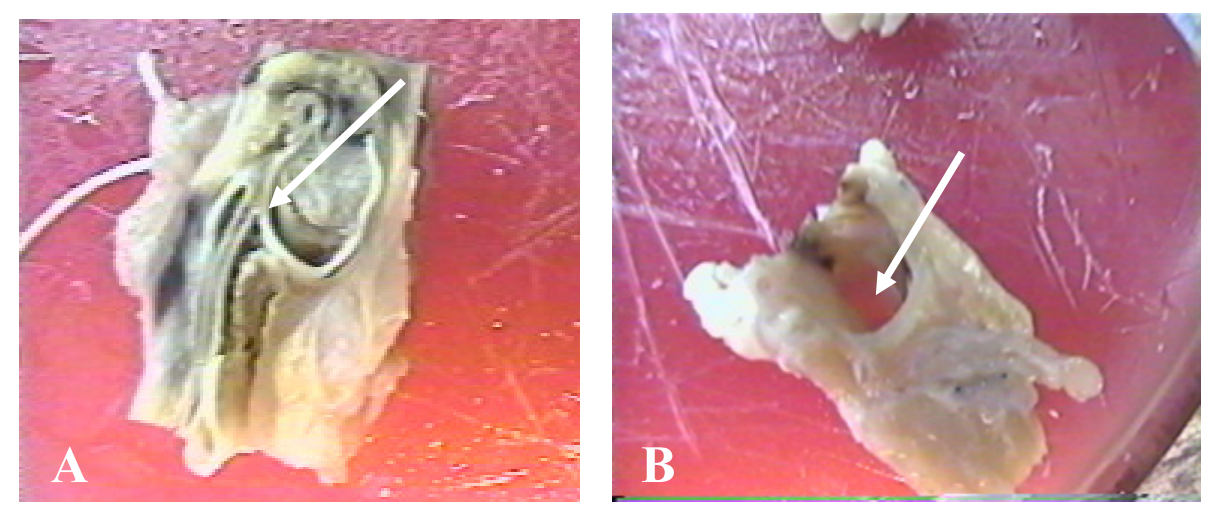

FIGURE 4 - Fragments of the specimen removed on the 28th postoperative day from the right inguinal region of dog no. 4: $\mathrm{A}$ - The latex biomembrane with impermeable polyamide is tortuous (arrow). B - cyst (arrow)

With the prolene prostheses, the peritoneum remained intact, with adherence of the epiploon in all cases. There was no visceral adherence. The prosthesis remained stretched and was fully incorporated in all dogs during the four periods of time.

With the impermeable latex biomembrane there was vascular neoformation, with an acute local polymrphonuclear inflammatory reaction at 7 days and a chronic morphonuclear inflammatory reaction with the presence of lymphocytes, histiocytes and monocytes 14, 21 and 28 days after surgery. Organized collagen deposition and total encystment of the biomembrane occurred in all cases during the four periods of time evaluated (Figure 5).

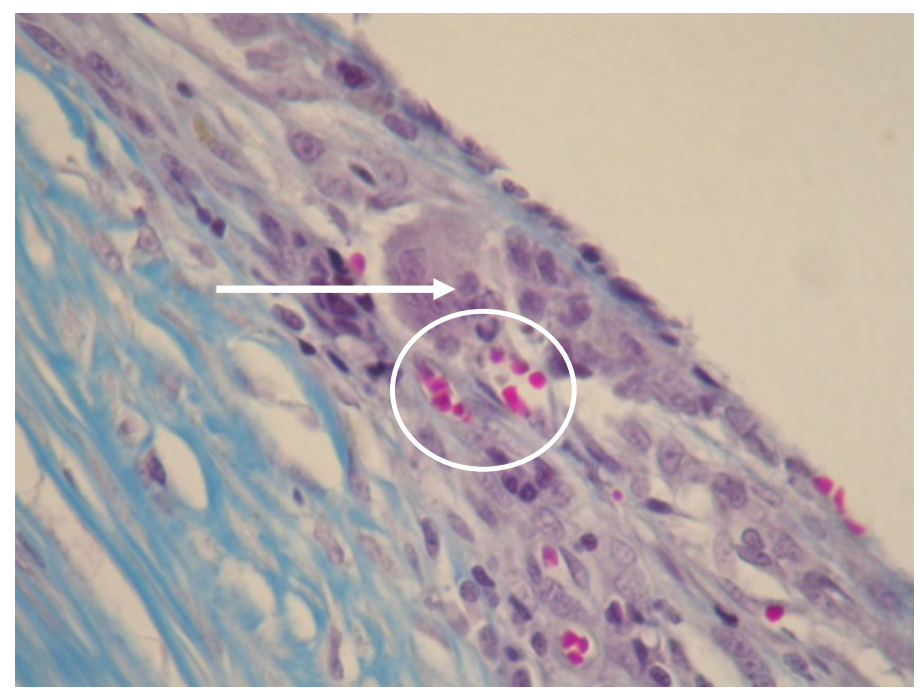

FIGURE 5 - Light photomicrograph obtained on the 28th day after surgery in the left inguinal region of dog number 6 (latex biomembrane with impermeable polyamide). Vascular neoformation is observed (circle), as well as a chronic lymphohistiocytic inflammatory process (arrow), organized collagen deposition and a cyst. No fibrosis occurred (Masson trichrome, 400x)
With the prolene prosthesis there was vascular neformation, with an acute polymorphonuclear inflammatory reaction at 7 days and a monomorphonuclear reaction at 14, 21 and 28 days, as well collagen formation, induction of tissue fibrosis and in the mesh of the prosthesis, with full incorporation into adjacent tissues during the four periods of time evaluated (Figure 6).

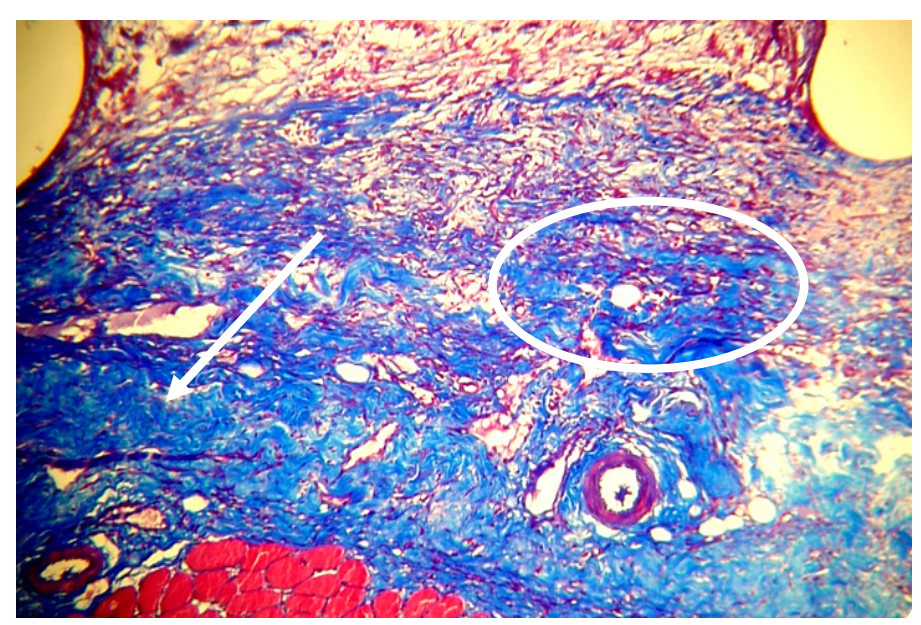

FIGURE 6 - Light photomicrograph of the left inguinal region of dog number 1 (prolene) obtained on the 7 th postoperative day. The presence of fibrosis is observed (circle) and the prolene prosthesis is fully incorporated into adjacent tissues (arrow). (Masson trichrome, 10x)

GROUP 2: At 28 day after surgery there was no macroscopic evidence of complications such as seromas, hematomas or infection.

With the latex biomembrane with impermeable polyamide the peritoneum remained intact in three cases, with epiploon adherence in only one dog. There was no visceral adherence, the biomembrane became tortuous and total encystment occurred in all dogs. 
With the latex biomembrane with impermeable polyamide there was vascular neoformation, a chronic morphonuclear inflammatory reaction with the presence of lymphocytes, histiocytes and monocytes, as well as deposition of organized collagen in all cases. There was no fibrosis. Total biomembrane encystment occurred in all cases.

GROUP 3: At 28 days after surgery there was no macroscopic evidence of complications such as seromas, hematomas or infection.

With the latex biomembrane with thick porous polyamide the peritoneum remained intact in one case and was ruptured in the other. Epiploon adherence occurred in both dogs but there was no visceral adherence. The biomenmbrane became tortuous and total encystment occurred in all cases.

With the porous thick latex biomembrane there was vascular neoformation, a chronic monomorphonuclear inflammatory reaction with the presence of lymphocytes, histiocytes and monocytes, as well as deposition of organized collagen in all cases. There was no fibrosis. Total encystment of the biomembrane occurred in the two cases evaluated.

GROUP 4: At 28 days after surgery, there was no external macroscopic evidence of complications such as seromas, hematomas or signs of infection.

With the latex biomembrane with fine porous polyamide the peritoneum remained intact, there was epiploon adherence in both dogs, but no visceral adherence. The biomembrane became tortuous and full incorporation was macroscopically observed in both animnals. There was vascular neoformation, a chronic monomorphonuclear inflammatory reaction with the presence of lymphocytes, histiocytes and monocytes, as well as deposition of organized collagen in all cases. There was no fibrosis. Microscopically, there was microcyst formation and partial incorporation of the biomembrane in both cases (Figure 7).

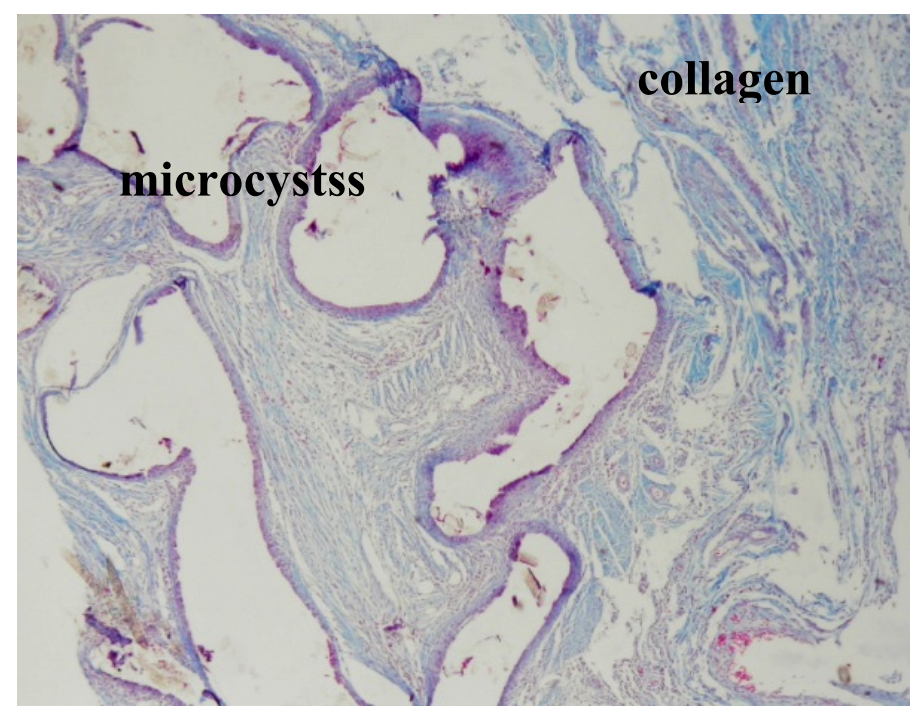

FIGURE 7 - Light photomicrograph of the left inguinal region of dog number 12 (latex biomembrane with 0.5 -mm porous polyamide) obtained on the 28th day after surgery. There is deposition of organized collagen and microcysts with biomembrane fragments are observed. There was no fibrosis (Masson trichrome, 200x)

\section{Discussion}

The objective of the present investigation was to assess the morphological aspects of the behavior of the latex biomembranes with four different structures surgically placed in the preperitoneal space of the inguinal region of dogs by videolaparoscopy using the TAPP technique.

Dogs were chose because their size is favorable and the anatomy of their inguinal region is closely similar to that of humans.

The "tire patch" principle mentioned by Stoppa ${ }^{9}$ with the use of a preperitoneal prosthesis and the principle of the "tension-free" technique of Lichtenstein ${ }^{8}$, in addition to the advantages of videolaparoscopic surgery in inguinal hernias ${ }^{10,17}$, form the tripod of support for the best results reported in the literature with the TAPP technique.

These facts, taken together with some good results obtained with the latex biomembrane such as induction of healing and biocompatibility, motivated the present investigation.

The fact that none of the 16 inguinoplasties performed in the present study showed any complications such as hematomas, seromas and infection confirms the essential importance of prosthesis sterilization and handling with the utmost aseptic care demonstrated in the literature during the Listerian era of surgery.

The occurrence of adherence of the epiploon along the peritoneal suture line has also been reported in the literature when the TAPP method is used in humans ${ }^{10,17}$.

Two important factors may explain why the membranes became tortuous at all four time points of evaluation: 1 - the biomembrane is extremely flexible because it has no supporting "skeleton", and 2-encystment of the biomembrane that permits it to remain free inside a cyst. Since the prolene prosthesis is incorporated into the tissues, it remains fixed and permanently accommodated.

The induction of collagen deposition and fibrosis with the consequent incorporation of the prolene prosthesis confirmed literature results, permitting us to state that the prolene prosthesis can continue to the applied as reinforcement of the inguinal region by the TAPP approach. However, the same does not apply to the impermeable latex biomembrane, which, although inducing collagen deposition at all four time points of evaluation, did not stimulate the formation of fibrosis and consequently was not incorporated. On the other hand, it maintained the important characteristics demonstrated by Mrué et al. ${ }^{13}$, Frade et al. ${ }^{14}$ and Sader et al. ${ }^{13}$ regarding vascular neoformation and induction of inflammatory activity.

In group 1 there was full incorporation of only the prolene prosthesis, which leads us to state that the lack of biomembrane incorporation was exclusively due to the characteristics of tissue reaction to the latex, since other factors that do not favor incorporation such as visceral pressure in the dogs and fixation of the prothesis only to the transverse abdominal muscle and to the pectineal ligament are features shared by prolene and latex.

The results obtained in this first group regarding the tortuosity of the latex biomembrane and the accommodation of the prolene prosthesis stretched in the inguinal region stimulated new investigations aiming at the creation of a "framework" or "skeleton" for the latex biomembrane that would also keep it stretched. 
The results for the group implanted with latex and impermeable polyamide were similar to those for the group implanted with impermeable latex, demonstrating that the addition of polyamide was not beneficial regarding the incorporation of the biomembrane. In the present study, polyamide was completely enveloped with latex, having no direct contact with tissues. The similarity of the results for the groups with and without polyamide suggests the possibility that the non-incorporation of the biomembrane was due to the characteristics of tissue reaction to latex more than to primary failure of polyamide as a support.

In a further attempt to improve the performance of the latex biomembrane, a new modification was introduced in its structure, rendering it porous, based on the results reported by Stoppa et al. ${ }^{7}$, Fitzgibbons et al. ${ }^{19}$, Dion and Morin ${ }^{10}$, McKernan and Laws ${ }^{17}$. The results obtained with the latex biomembrane with 1 -mm thick polyamide in group 3 were similar to thouse obtained for the group implanted with latex with impermeable polyamide, demonstrating that the presence of pores in the biomembrane with thick porous polyamide did not contribute to improving the results regarding incorporation.

The orifice detected in the parietal peritoneum of a dog in the group implanted with latex plus impermeable polyamide and in a dog in the group implanted with latex plus thick porous polyamide may have been due to technical failure to properly close the peritoneum, favored by its tenuous thickness in these animals.

The latex biomembrane with fine porous polyamide maintained the same tortuosities as observed in the remaining groups implanted with the latex biomembrane, although with full incorporation. However microscopic analysis of the two cases demonstrated vascular neoformation, an inflammatory reaction, collagen deposition without fibrosis and microcyst formation, but with partial incorporation of the biomembrane. This showed that the reduced thickness of the porous biomembrane was of some benefit, in agreement with literature reports ${ }^{10,11,17,19}$ that demonstrated the need for pores in the prosthesis for intermingled fibroblast proliferation to occur with consequent incorporation. These facts suggest that a less thick biomemnbrane appears to be a factor influencing incorporation into adjacent tissues. We speculate whether incorporation of the 1-mm thick porous biomembrane would be possible after a longer time of observation.

Analysis of the results as a whole permits us to state that: 1) although in the present study the prostheses made of prolene, impermeable latex, latex plus impermeable polyamide and latex plus $1-\mathrm{mm}$ and $0.5-\mathrm{mm}$ thick porous polyamide did not induce infection in the inguinal regions, the possibility of infection could not be excluded if a larger number of dogs is used. 2) The biomembranes made of latex, latex plus impermeable polyamide and latex plus 1-mm thick porous polyamide, although inducing healing by vascular neoformation and collagen deposition, became encysted, without being incorporated into adjacent tissues and suffered tortuosities when placed in the preperitoneal space of the inguinal region by the TAPP technique. These characteristics do not recommend their use in this type of inguinoplasty. 3) The latex biomembrane with $0.5-\mathrm{mm}$ thick porous polyamide induced healing by vascular neoformation and collagen deposition and was partially incorporated into adjacent tissues, although forming multiple microcysts. These characteristics suggest that the fine porous latex biomembrane yields better results than the other latex biomembranes when implanted by the TAPP technique.
New studies with the biomembrane involving adjustments in thickness, pore size and types of associated material may eventually optimize the results so that the material may be used in inguinoplasty.

Andrade et $a l .{ }^{20}$ assessed macroscopically and microscopically the behavior of a double-face prosthesis (latex biomembrane/polypropylene net), using as control a polypropylene net fixed in the contralateral inguinal region. The authors observed that the double-face prosthesis has advantages over the propylene one in terms of the prevalence and degree of adherence with the epiploon, with the additional advantage of the potential incorporation into tissue observed with polypropylene and of the biocompatibility of latex.

\section{Conclusions}

Under the conditions of the present study, macro- and microscopic morphological evaluation of the behavior of the latex biomembrane implanted in the preperitoneal space of the inguinal region of dogs by videolaparoscopic inguinoplasty using the preperitoneal transabdominal technique permitted us to conclude that:

1 - The biomembranes made of impermeable latex, latex with impermeable polyamide, latex with $1-\mathrm{mm}$ thick porous polyamide and latex with $0.5-\mathrm{mm}$ thick porous polyamide of the same thickness as the prolene prosthesis do not induce local infection when asepsis norms are followed.

2 - The biomembranes studied suffer tortuosities in the preperitoneal space but, although having characteristics of the induction of the healing process, stimulating vascular neoformation, an inflammatory reaction and collagen deposition, they do not induce fibrosis and suffer encystment and, except for latex biomembranes with $0.5-\mathrm{mm}$ thick porous polyamide, are not incorporated separately into adjacent tissues.

3 -Latex biomembranes with and without polyamide are not recommended for separate use in preperitoneal inguinoplasties.

\section{References}

1. Nyhus LM, Stevenson JK, Listerud MB, Harkins HN. Preperitoneal herniorrhaphy; a preliminary report in fifty patients. West J Surg Obstet Gynecol. 1959;67:48-54.

2. Shouldice EB. The Shouldice repair for groin hernias. Surg Clin North Am. 2003;83:1163-87.

3. Harrison JH. A. Teflon weave for replacing soft tissue defects. Surg Gynecol Obstet. 1957; 104:584-90.

4. Nyhus LM, Pollack R, Bombeck CT, Donahue PE. The preperitoneal approach and prosthetic buttress repair for recurrent hernia. The evolution of a technique. Ann Surg. 1998;208:733-7.

5. Rives J. Surgical treatment of the inguinal hernia with the dracon patch. Int Surg. 1967;47:360-1.

6. Usher FC. A new plastic prosthesis for repairing tissue defects of the chest and abdominal wall. Am J Surg. 1959;97:629-33.

7. Stoppa RE, Warlaumont CR, Rives JL. The use of Dracon in the repair of hernias of the groin. Surg Clin North Am. 1984;64:269-85.

8. Lichtenstein IL, Shulman AG, Amid PK, Montlor MM. The tensionfree hernioplasty. Am J Surg. 1989;157:188-93.

9. Stoppa RE, Petit J, Henry X. Unsutured Dracon prosthesis in groin hernias. Int Surg. 1975;60:411-2.

10. Dion YM, Morin J. Laparoscopic inguinal herniorrhaphy. Can J Surg.1992;35:209-12. 
11. McKernan JB, Laws H. Laparoscopic repair of inguinal hernia using a totally extraperitoneal prosthetic approach. Surg Endosc. 1993;7:26-8. 12. Arregui ME, Navarret J, Davis CJ, Castro D, Nagan R. Laparoscopic inguinal herniorrhaphy techniques and controversies. Surg Clin North Am. 1993;73:513-27.

13. Mrué F, Coutinho-Netto J, Ceneviva R, Lachat JJ, Thomazine JA, Tambelini H. Evaluation of the biocompatibility of a new biomenbrane. Mat Res. 2004;2:273-83.

14. Frade MAC, Coutinho-Netto J, Foss NT. Chronic phlebophatic cutaneous ulcer: a therapeutic proposal. Int J Dermatol. 2001;40:237-40. 15. Sader SL, Coutinho-Netto J, Barbieri-Neto J, Mazzeto AS, Alves-Jr PA, Vanni JC, Sader, AA. Substituição parcial do pericárdio de cães por membrana de latex natural. Rev Bras Cir Cardiovasc. 2000;4:338-44.
16. Cumberland VH. A preliminary report on the use of prefabricated nylon weave in the repair of ventral hernia. Med J Aust. 1952;1:143-4.

17. McKernan JB, Laws H. Laparoscopic preperitoneal prosthetic repair of inguinal hernias. Surg Rounds. 1992; 15:597-608.

18. Howard JN. A CIOMS ethical code for animal experimentation. WHO Chron. 1985;39:51-6.

19. Fitzgibbons RJ, Salerno GM, Filipi CJ, Hunter WJ, Watson P. A laparoscopic intraperitoneal onlay mesh technique for the repair of an indirect inguinal hernia. Ann Surg. 219:1994;144-56.

20. Andrade LC, Ceneviva R, Coutinho-Netto J, Silva Jr OC, Santos JS, Sukeda DH. Aspectos morfológicos da utilização intraperitoneal de prótese de dupla face na inguinoplastia em cães. Rev Col Bras Cir. 2009;36:431-7.

\section{Correspondence:}

Luiz Henrique de Sousa

Avenida T4, 1190/300 Setor Bueno

74230-035 Goiânia - GO Brasil

Tel.: (55 62)9611-0276

drluizhs@,terra.com.br

Conflict of interest: none

Financial source: none

${ }^{1}$ Research performed at Division of Gastroenterolgy, Department of Surgery and Anatomy, Faculty of Medicine of Ribeirao Preto, University of Sao Paulo (FMRP-USP), Brazil.

Presented at the XII National Congress on Experimental Surgery of the Brazilian Society for Development of Research in Surgery-SOBRADPEC, 2011 October 26-29 Ribeirao Preto-SP, Brazil. 